se
191
$W 5 C 5$

A Grain of Wheat

F. Chodat

UC-NRLF

|| || || || || || || || || || ||.|||||||||||||||

$\$ C \quad 18$ 208

m

0

(5)

0

Lid 


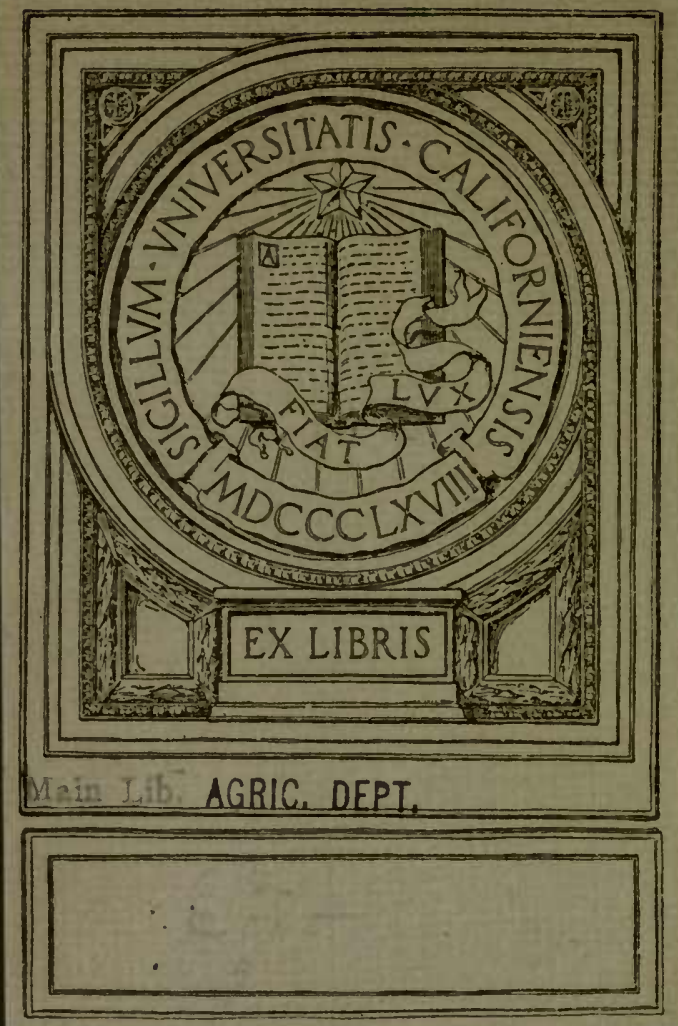



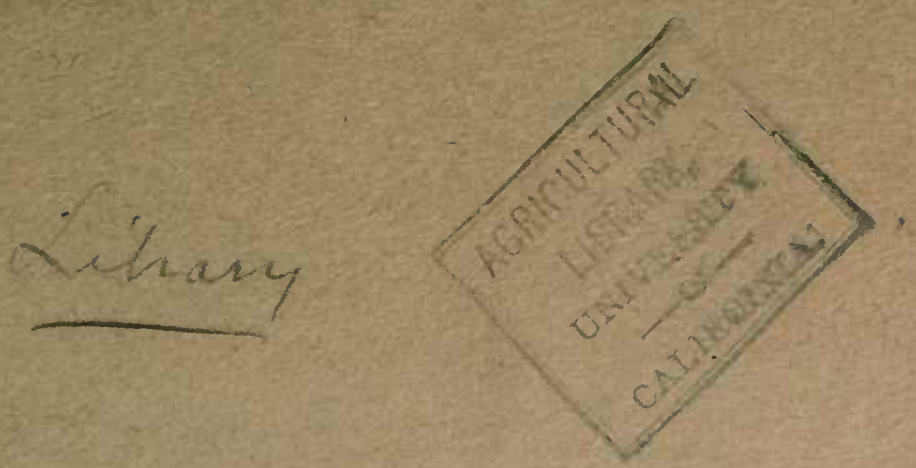

1130

\section{A GRAIN OF WHEAT}

BY R. CHODAT

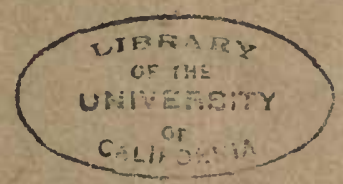

Reprinted from the Popular Sciknce Montuly, January, 1913.

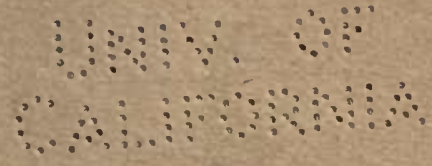





\section{A GRAIN OF WHEAT ${ }^{1}$}

BY R. CHODAT

PROFESSOR OF BOTANY AT THE UNIVERSITY OF GENEVA, SWITZERLAND

PEOPLES truly rich are those who cultivate cereals on a large scale.

Scores of investigators in all civilized countries devote themselves unceasingly to a problem of great social significance, viz., the increase of the national wealth through progress in agriculture. The least discovery in this field, whatever the political journals may say, is more important for a country than a change of the party in power. For it is the history of discoveries and inventions-in the domain of nature, as well as in the intellectual field-that constitutes the real history of civilizations.

Thus the modern improvements in the industry of milling in connection with better transportation facilities have helped to provide better bread for all classes and have rendered famine impossible in the Europe of to-day.

Is it then any wonder that since the most remote antiquity germinating wheat has been the symbol of mysterious and hidden life, that in their religious ceremonies the ancients attached so much importance to cereals offered on the altar, that our modern artists, putting aside the petty themes of political events, have glorified the beauty and nobility of harvests, the poetry and mystery of sowing, in justly renowned paintings? Roty's admirable sower on the French coins, who symbolizes the value of this idea, shows us the highest art seeking its inspiration at the very source of civilization-the culture of wheat.

I do not wish to overtax your attention or indulge overmuch in scientific pedantry by enumerating to you, together with their botanical characteristics, the different kinds of wheat which have been and are still cultivated. I shall merely give you as much as is essential for my purpose. The most competent botanists in this field agree in recognizing at least three species of wheat:

1. Einkorn (Triticum monococcum).

2. Polish wheat (Triticum polonicum).

3. Wheat (Triticum sativum).

These distinctions are based not only on morphological characters, but also on a character which is accepted on good grounds as usually

${ }^{1}$ Presented before the General Meeting of the Societe des Arts, Geneva, Switzerland. Translated from the French by Maude Kellerman. 
separating species from varieties, that is, their sterility when crossed among themselves, or their failure to produce fertile offspring. Attempts to cross these types have never given results.

Ordinary wheat may be divided into numerous varieties or subspecies, reciprocally fertile, which are grouped about the following subspecies:

\author{
Emmer (T. dicoccum). \\ Spelt ( $T$. spelta). \\ Wheat proper (T. tenax).
}

The first two subspecies differ from the third in that the ear has a fragile rachis and the grains remain covered by glumes which must be removed by a somewhat complicated process, whereas in the third species the grains on ripening fall from the ear the rachis of which is not articulated. I shall give here only what is most essential for the understanding of what is to follow. Now, it is evident that emmer and spelt are inferior to true wheat because of the fragility of the rachis of the ear and because of their enclosed grains. Whenever it is possible wheat is grown instead of emmer or spelt.

Not to prolong the discussion of these classifications, let us say at once that wheat proper is represented in cultivation in various parts of the world by a considerable number of varieties, but it is difficult even for the specialist to distinguish them. One of these varieties, having a non-articulated rachis (Triticum durum), the hard wheat of the Mediterranean countries, is so closely related to emmer that the systematic affinity of the wheats with an articulated rachis and those with a non-articulated rachis can not be questioned. ${ }^{2}$ Each year, in agricultural experiment stations organized according to the principles of Vilmorin, Rimpau or Svalöf, new races are brought to light and are tested out in suitable soils and climates. I do not wish to tire you by a dry enumeration of all these forms; even had I the time for it I should not be competent to perform this task.

Which of all these varieties of cereals first appeared in cultivation? To this question we may reply that it is certain to-day that emmer was cultivated by the Egyptians from the time of the first dynasty, or about 6,000 years ago. The glumes preserved in the tombs show that the grain was already at that time freed from its envelopes by the use of special machines; it was not simply flailed or tramped out by cattle. Einkorn and emmer have also been found among the débris of the granaries of the lake-dwellers of Switzerland. Hard wheat, which of all the kinds of wheat proper most nearly resembles emmer, has also been cultivated in Egypt since very ancient times. If we regard the

"Aaronsohn, Aaron, "Agricultural and Botanical Explorations in Palestine," Bulletin No. 180, United States Department of Agriculture, 1910, Bureau of Plant Industry, 64 pp., 9 pls., 12 text figures. 
matter from an evolutionary standpoint, according to which related races, varieties and species had a common origin, we can arrive logically at but one conclusion, namely, that the most ancient wheats were those with a fragile rachis. One arrives at the same conclusion on comparing the cultivated barley, having an articulated rachis, with the wild barley which has a fragile rachis.

The well-preserved emmer glumes in this bottle which I am going to have passed around were found at Abusir in the tomb of the king Newoser-re (Dyn. v. 2400 B.c.). This material was very kindly sent me by the Oriental Society of Berlin.

If, on the other hand, we look to Europe and Asia to see in which countries these ancient cereals are still cultivated, we shall find them in the northern Jura, in the countries of the Basques, the Servians, the Swabians and the Bactrians of Persia. We see that these cereals have maintained themselves only in mountainous countries or among the peoples most remote from the centers of civilization. The cultivation of emmer has long since disappeared from the fertile plains of Egypt, where it was superseded by that of hard wheat.

Knowing, therefore, that the wheats cultivated in most ancient times were those with a fragile rachis, we are confronted by a second question: Where is the home of this type of wheat? In what country did our first parents, our prehistoric ancestors, find this plant, most precious of all plants?

As for the einkorn, we know its home since the botanist Balansa found it in Asia Minor. It is true that Balansa's wild plant differs from the cultivated einkorn in certain characters and it has been named Triticum monococcum, var. agilipoides. But it has already been noted that this species is too distinct from wheats to allow it to be considered as their prototype.

For more than a century botanists and historians of civilization have sought for the home of wheat. In vain have all the resources of comparative morphology been employed, as well as those of history and philology. The origin of wheat remains shrouded in mystery. The ancients attributed its introduction into the world of men to some beneficent goddess, thus putting the mystery of its first cultivation back of all written history.

A botanist of great merit, Count Solms Laubach, weary of this discussion, finally advocated the idea that the wheat of the present day, with its numerous varieties, might be the descendant of plants which have to-day disappeared, either because their home was submerged by the sea or because they were the result of a convergence of several species deviating in the same direction or mixed in cultivation, which would make the determination of their origin almost impossible.

In the universities the view has generally been held that the home 
of the wheat would always remain unknown and that our cultivated species had been so greatly modified by cultivation that they scarcely resembled the wild species which served our prehistoric parents in their conscious or unconscious attempts at artificial selection. This transformation, it was said, had required ages of time, and it was not overlooked that it had also required extraordinary perspicacity on the part of these half savages who succeeded in producing from an insignificant grass the vigorous and precious cereal of to-day. It was admitted, thus, that prehistoric man was endowed with a divining sense more remarkable than that of the scientists of the present time, who, in the domain of agriculture, have never achieved results equal to this. To support this idea it might be maintained that the more primitive the people the more acute is its sense of observation. Book science very often sterilizes the excellent mentality natural to youth and also limits the imagination.

However, I remember that when for the first time I found wild cabbage growing on rocks at the seashore remote from all cultivated fields, I was struck by the fact that even with my limitations of an educated man and with all the mental deformation attendant on scientific specialization which leads one away, they say, from common sense, I should nevertheless, it seemed to me, not have hesitated, in case of need, to try this plant as food, so inviting was its appearance. Last year, in my botanical trip along the coast of Portugal, I was able to see that the Portuguese peasant, who has kept so many vestiges of the past in his dress, his domestic animals (long-horned cattle), his cart and his customs, still uses the cabbage (Covo-gallego) as primitive peoples would; the flower tops are simply boiled. There is a far cry from this cabbage still so near its primitive state to the numerous varieties which the agriculturists have introduced into our European cultivation.

There is, then, reason to believe that primitive man found the plants suitable for cultivation already showing the principal attributes which make them useful; he found the cereals, he did not create them. In other words, cereals are the cause of civilization, not civilization the cause of cereals.

Alphonse de Candolle, the illustrious father of the president of the - Société des Arts, in his classic work on the origin of cultivated plants, in 1883, says:

The Euphrates region, lying about in the middle of the zone of cultivation [of wheat] which formerly extended from China to the Canary Islands, was very probably the principal habitat of the species in very early prehistoric times. Perhaps it extended towards Syria, as the climate is very similar, but to the east and to the west of western Asia wheat has never existed except in a cultivated state, antedating, it is true, any known cirilization. 
This brings us to the main issue of the question which I wish to study with you.

About 1902 two German botanists, well known in Geneva, Ascherson and Schweinfurth, called the attention of a young agronomist, Mr. Aaron Aaronsohn, who was destined in later years to become director of the Haifa Agricultural Station in Palestine, to the scientific and historic interest of determining the truth of a suggestion made by Kotschy. This collector brought back from Syria a fragment of a wild plant which Körnicke, an authority on cereals, recognized as a form of Triticum dicoccum and which he made a variety under the name of $T$. dicoccum dicoccoides.

From this mere indication Körnicke drew the same conclusions as those A. de Candolle had reached by another road, $i$. e., that wheat must be indigenous to Syria. In the course of a geognostic expedition in Upper Galilee to the north of Lake Tiberias, Mr. Aaronsohn gave his attention to this question, although he was very dubious about being able to answer it.

As a matter of fact, modern botanists who have studied the flora of Syria, such as Dr. Post, have not confirmed Kotschy's doubtful indication. On the first expedition Mr. Aaronsohn found nothing, but urged by his friends in Berlin he went to this same region again, and this time his efforts were crowned with success. In June, 1906, being at the north of Lake Tiberias at Rosh Pinah, he found a single specimen of the wild emmer (Triticum, dicoccum dicoccoides) growing in a rocky fissure. Complete success came, however, only on leaving Rasheya, where wild wheat abounded in uncultivated ground. Having climbed Mt. Hermon, he descended on the opposite side, and towards the village of Arny wild wheat was also very common and showed here an extraordinary variety of forms; black glumes or only partly black, black or colorless heads, smooth or hirsute glumes, glumes sometimes resembling those of Triticum monococcum (einkorn) or Triticum durum (hard wheat), heads of the type of $T$. polonicum, etc. Among these plants there was also the wild einkorn ( $T$. monococcum agilipoides. This excessive variation, the abundance of these plants, their distribution on the slopes of Mt. Hermon from an altitude of 1,500-2,000 m., all show that the plant is certainly indigenous. It is a known fact that our cereals do not spread beyond cultivation in any country and that however extended their cultivation may be they never become subspontaneous. In order to establish itself in any locality a plant must hold its own against competitors which, masters of the soil from time immemorial, have been selected to fit the soil and climate. Moreover, emmer is not cultivated anywhere in Palestine. This wild wheat is furthermore a different plant from any known in cultivation, a polymorphous race, no doubt, but a distinct 
one, to which Körnicke had already given the varietal name dicoccoides. No intermediate form between this wild plant and those cultivated in Palestine has been found. Thus everything tends to show that wheat is indigenous to Mt. Hermon. Somewhat later, Mr. Aaronsohn discovered Secale montanum, the wild rye, in Antiliban. For philological reasons it had formerly been thought that this was indigenous to Europe. From now on we must bear in mind that this cereal also has its center of distribution somewhere in Asia Minor.

That wheat was indigenous to Palestine was to be confirmed somewhat later by the same explorer. In 1908, while on a mission for the Turkish government, Mr. Aaronsohn discovered wild barley, already known at other stations, in the Moab country on the left bank of the Dead Sea, above El Mazra-a; towards Wady Wahleh monoliths occur in large numbers and round about are many chipped flint implements. The Jewish savant could not keep his fancy from roaming. He went back in spirit to that far-away epoch, more ancient than all written history, when urged by hunger while crossing these steppes, primitive man first tried these savory grains and discovered cereals.

A little later in this same region of the Dead Sea, while on a second expedition, Mr. Aaronsohn found emmer in great abundance, towards Tel Nimrim, in the valley of the Jordan, at Ain-Hummar, on the plateau of Es-Salt.

When one considers the fact that the grains of wild wheat are not inferior either in weight or size to those of the best cultivated species it would be impossible not to arrive at the conclusion that primitive man did not create cereals, he found them.

One can imagine the nomads of the hills and mountains of Palestine, giving these precious seeds to the inhabitants of Mesopotamia, who were better situated than themselves for the testing of crops and who succeeded with them in their rich alluvial plains. Glancing at the Assyrian bas-relief, we are struck by the great importance given by this people in their ceremonies to the mystery of the seed which contains within itself the essence of life and, in consequence, the intense interest which they manifested in all agriculture.

One of the most striking things in economic history is the rapidity with which a new food or useful plant spreads even to little-civilized countries. Schweinfurth, in his famous voyages to the heart of Africa, found tobacco grown by the most primitive peoples. Hooker, exploring the high valleys of the Himalayas, found the potato cultivated by the Lepchas and the people of Nepaul, scarcely half a century after its introduction into Europe as an important cultivated plant.

I have told in detail of the important discovery of Aaronsohn. Let us see now what practical and scientific results can come from it. 
In order to do so it is necessary to explain to you as briefly as possible the present state of biological science and the modern way of considering the problems relating to species.

Modern botany, abandoning the ancient methods which depend more on metaphysics and speculation than on experiments, has given up the idea of discovering the origin of species by the prevalent method of comparison and reasoning. The separation of forms, of varieties and of species, as it is made by systematists, the herbarium specialists, is based on judgment; it depends essentially on the degree of intuition of the botanist who compares and draws conclusions. I do not mean to say here that the methods of this science are conjectural, but I may be permitted to say that it is only an outline of a science, that it is provisional knowledge, a first attempt at classification. More precise methods are necessary in order to resolve serious biological questions. The best representatives of contemporary biological science are much less hurried than their predecessors; they have acquired the conviction that there is no short cut to truth. The scientific highway is paved with difficulties. In this explanation, then, I shall not touch upon the evolutionary speculations of Darwin or others, but shall give my time exclusively to exact data.

Contemporary biology accepts the constancy of types as a wellestablished fact. It has discovered that this constancy is experimentally demonstrable if the following facts, not known to Darwin and his followers, be taken into account.

Every species in its natural state, and often even in cultivation, includes a large number of forms which were formerly considered variations, but which, analyzed by modern methods, appear to be constant types, all of which taken together form the Linnean species. In order to discover these small constant species which ordinarily live mixed together, it is necessary to segregate them. Vilmorin had already recognized that unequivocal results could not be obtained in the study of variation if one starts with an isolated plant or even with a single seed. A single grain of wheat may be the ancestor of innumerable generations. If these isolated grains, carefully catalogued, be sown separately, it is seen that they give birth to constant-races or lines which are called pure, because they are without mixture. To evaluate these lines and differentiate them from other lines, we must not consider the isolated individual, but rather note the character of the descendants as a whole by means of experimental pure cultures. The individuals of the same race, of the same line, may differ very much according to their age, nutrition, position during the embryonic or ontogenic development, but their descendants taken as a whole are identical. In a pure race, the dwarfs as well as the giants give birth 
to a mediocre line having the same average size (and other values which I can not cite here). In other words, the sum of the descendants is identical with the sum of the ascendants.

Each race differs from the others in form, stature, hardiness and chemical composition. The name population has been given to the mixtures of races, such as nature gives us in a meadow or such as we have in cultivation when segregation has not been carried far enough, that is to say, when pure lines which can be distinguished have not been separated grain by grain. This practise of selection, according to Vilmorin, has already been tested not only in the vast field of theoretical botany, but also in that of applied botany. At Svalöf, Sweden, cereals are selected according to this principle by evaluating the differences by numerical methods. All agricultural Europe follows with special attention the classic experiments of Nilson and his collaborators.

Except for the very rare phenomenon of spontaneous variation (mutation) we can by beginning with these pure lines operate in a practical way, with almost mathematical certainty, the probable error being minimal. In cereals, and especially in wheat, the characters to be studied which will be constant for a given race are: stooling, regularity of growth (that is, greater or less individual variation), average weight of the grains, resistance of the straw to lodging, length of the straw, form and length of the heads, composition of the grain (starch, sugar, nitrogen, fat, etc.), disease-resistance. In the short time at my disposal I can not explain to you the ingenious methods used to determine with precision these different characters. I wish to add only one thing. Each of these characters or their combination in pairs or groups determines the probability of success and good harvest in a given locality, and, in consequence, the more constant forms, the more pure lines there are, the more prepared will scientific agriculture be to furnish to cultivators races which will suit their soils. Now if you consider that these problems are among those that chiefly interest mankind, which demands each day its daily bread, you will understand that the slightest discovery which makes for the betterment of cereals means a noticeable increase in the wealth of a nation. If France is one of the richest countries of the world it is because her wheat production is superior, in respect to her territory, to that of all her competitors.

Now, modern agriculture, given new life by botany, has obtained in France, Germany and other civilized countries, a considerable number of these varieties, starting from cereals introduced into our country in the course of the long history of civilization; that is, from times more ancient than any documents written on parchment or carved in stone. 
But let us remember the important results of Aaronsohn's discoveries: Primitive man, even he who chipped the flints abounding about the menhirs of the Moab country, as he sought his food in the steppes, found fields of cereals waving in the breeze just as the graceful heads of Stipa sway in the breeze of our fields of our canton of Valais. The wild wheat, Triticum dicoccoides, with its large grains, must have immediately caught the attention of a primitive people, interested in nature as are all peoples whose eyes have not been closed and whose sense of observation has not been dulled by too much book learning.

Is it not a singular coincidence that this young Jew, Mr. Aaronsohn, should rediscover in Judea the origin of our cereals, of our civilization? There is material in that for a philosopher or a historian to write a moving page. I have the pleasure of counting Mr. Aaronsohn among my botanical friends, and I may say to you that rarely has an important discovery been made by a more genial and charming man. Those who say that man is master of his fate may well cite him as an example. But let us rather listen to him:

Jewish Agricultural Experiment Station Haifa, Palestine

26 Jan., 1911

Monsieur Chodat,

Professeur a la Faculte des Sciences, Genève.

Dear Sir: I have just received your kind letter of the $3 \mathrm{~d}$ inst., which recalled to me our agreeable and interesting conversations during the Congress at Brussels. I am very much flattered to learn of the subject that you have chosen for the annual meeting of the Societe des Arts.

I shall be glad to send you the "corps du delit" which you wish; I shall also take the liberty of sending some photographs taken last June which will give you an idea of the appearance of the fields where my Tritioum flourishes. You will doubtless be glad to learn that we have this year sown more than an acre of Triticum dicoccoides. We intend to study the value of this plant for forage, etc. I had the good fortune to discover in Upper Galilee this year a spontaneous hybrid of Triticum and Filops, and there also exists already a wheat with a non-articulate rachis, arising from a cross of my Triticum and a cultivated wheat. Thus you see that we are rapidly advancing towards the realization of our dream. In the different experimental fields where my Triticum has been grown it has resisted rust very well, and this for three or four successive years while many check varieties succumbed to this disease. In these times of "unit characters" it should not be difficult to fix this special property of disease-resistance, and you will at once realize the practical significance and the economic value of this character.

As for the problem of the origin of civilization or the origin of wheat culture, I have resolved upon a new method of attack. I had first taken up the study of adventitious plants accompanying our cereals. Thus the discovery of Lolium temulentum, quite spontaneous in a given region, far from all cultiva tion, would be a sufficient reason, in my opinion, for inaugurating a search in this neighborhood for the cradle of our cereals. Now, I am on another trail. 
I wish to study the eryptogamic diseases of my wild wheat in order to try to discover if among them there are any peculiar to wheat in other regions and which here would attack other plants. We could then say this or that cryptogam was carried by cereals and would be found in the same situation in relation to wheat, as certain phanerogamic satellites such as Lolium temulentum, Githago segetum, etc., etc.

I am sending with this letter a small photograph showing our workmen sowing Triticum dicoccoides with a drill. I shall not conceal from you that I am very proud that when for the first time since prehistoric times man has again tried sowing the prototype of wheat, this work has fallen to Jews (escaped from the ignoble massacres of Russia), Jewish teams working on Jewish ground, the historic cradle of the race.

Yours sincerely,

\section{A. Aáronsohn}

You perceive the wide field which this discovery has opened up. The utilization for new needs of new races of wheat to be segregated from this wild material, that is, from the polymorphic plant populations of the hills of Judea, the extension of the cultivation of cereals to arid regions or mountainous zones, where it has hitherto not been possible.

But there is more than that. We possess now, and Mr. Aaronsohn alludes to it in his letter, a second method of improving wheat by the method of selection, growing pure races from single seeds.

We can, by crossing, create new races and in this domain modern methods have a startling precision. They say that the man who suddenly had a new world revealed to him by the microscope lost his reason. To-day, placed in the presence of the facts brought to light by modern biological analysis, we can see in our minds an infinite line of discoveries which were not even suspected by the generations preceding us.

Here, in a few words, are the results already obtained:

They lead us to suppose the existence of essential representative particles within the germ cells of plants. These particles may be compared to the atoms which chemists suppose to exist in the inanimate world. These are the biological elements, the "organic corpuscles" as Buffon would have called them. We call them "gens." The body of the plant with its diverse characters is then only the exterior manifestation of these "determinants." We suppose, then, that each char" acter manifested is determined by a "gen," a "determinant." To constitute an organism with its characters there must be an association of gens.

For the sake of similarity in studies on heredity plants belonging to the same systematic grouping, the same genus or the same species, are usually compared. Only the characters in which these two plants differ are taken into account. For example, a race $X$ will differ from 
a race $Y$ by three characters, $i . e$., by the gens $A B C$ (for example, $A=$ long head ; $B=$ awned glumes; $C=$ rust resistance), to which the race $Y$ opposes $a b c$. These are antagonistic characters $(a=$ short head; $b=$ awnless glumes; $c=$ capacity for rust infection). $A$ is the antagonist of $a, B$ of $b$, etc. But $A$ is not antagonistic to $b$ or $c$, nor $B$ to $a$ and $c$.

As long as the plant is self-fertilized, the mosaic of its characters is maintained. But if it is fertilized by a distinct race several cases can arise in the course of successive generations. The product called a hybrid $\left(\mathrm{F}_{1}=\right.$ filius 1$)$ is evidently the sum of the two parents $(X+Y)$; if forms not closely related to each other are crossed, the hybrid generally takes a form intermediate between the two parents. We shall not speak of these hybrids here, for they are generally sterile and practically useless for cereal culture. If, on the other hand, closely related forms are fused in the hybrid $\left(\mathrm{F}_{1}\right)$ the characters of the father or the mother exclude those of the other parent; one of the parents seems to have been absorbed by the other. Then we say that the character of the father or of the mother dominates or vice versa. Let us take two parents $X$ and $Y$, differing in the antagonistic characters $A B C$ for $X$ and $a b c$ for $Y$. The hybrid $\left(\mathrm{F}_{1}=X+Y\right)$ will have the appearance $A, B, C$, if the total gens of $X$ dominate those of $Y$, or the appearance $a, b, c$ in the contrary case. In other words, one of the parents may seem to be absorbed by the other. But it often happens that if $A$ dominates $a, b$ dominates $B, c$ dominates $C$.

But if this hybrid $\left(F_{1}\right)$ is allowed to fertilize itself, its direct descendants, $i$. e., the second generation $\left(\mathrm{F}_{2}\right)$, show that the character or characters which had disappeared reappear in a proportion which can be predicted with almost mathematical certainty. I can not take the time to explain to you the details of this phenomenon. But the most astonishing thing is that among the descendants of the second generation $\left(\mathrm{F}_{2}\right)$ (that is, the descendants of the hybrid by self-fertilization) there are (1) those resembling the father exclusively $(X)$, or the mother $(Y)$; (2) new forms, $i$. e., those in which a part of the paternal and maternal characters are combined in a new mosaic.

To choose a very simple example, if the two parents differed by their two pairs of characters $A B$ and $a b$, the hybrid of the first generation $\left(\mathrm{F}_{1}\right)$ would bear the apparent characters $A B$ or $a b$, that is, it would resemble the father or the mother exclusively, according to the predominance; that of the generation $\left(\mathrm{F}_{2}\right)$ would comprise individuals of different sorts: $A B, A b, B a, a b$. The two combinations $A b$ and $B a$ are new.

If, in a second case, the antagonistic gens are $A B C$ for $(X)$ and $a b c$ for $(Y)$, the first generation might be $A B C$, but in the second 
we should have a larger number of categories of types; now, of these types there would be eight categories which would be constant. These would be $A B C, A B c, A b C, a B C, A b c, a B c, a b C, a b c$; two of these types repeat the primitive parents, the others are new. If these latter are not allowed to fertilize each other or to be ferilized by other forms, but are self-fertilized, they will be constant in their descendance, which will behave like a new stable species.

From this we see that the mosaics of gens, which constitute the hereditary capital of species and varieties, are dissociable and that the gens, in the phenomena preceding or accompanying fecundation, execute a sort of chassé-croisé, the final result of which is determined by the laws of probability.

The number of types and new forms increases rapidly with the number of antagonistic characters. For 2 antagonistic gens there will be 4 types; for 3 gens, 8 types; for 4 gens, 16 types; for 5 gens, 32 types; for 6 gens, 64 types; for 7 gens, 128 types-and these types are constant from the second generation (in which they appeared) on.

Here we have infinite perspectives which appear on our new scientific horizon.

But to obtain these remarkable results with the desired mathematical certainty we must start with biological unity, with a pure line, with a single grain of wheat, the parent of a whole line similar to it.

From this we see the importance of Aaronsohn's discovery; it will allow us to do methodically in a few years all that 6,000 years of cultiration and unconscious selection have gained for us and perhaps also to combine and associate characters which escaped the intuitive observations of primitive peoples.

For example, we can associate the hardiness of the wild wheat with the vigor of growth of a cultivated wheat, the rust resistance of a wild variety with the seed quality of a cultivated variety, etc. ${ }^{3}$

But wheat is not for agriculture, wheat is to make bread. This making of bread is almost as old as the cultivation of wheat, and yet the conditions of fermentation necessary to raise the dough under the influence of leaven are still insufficiently known. We know that in this sour dough, the natural leaven, there are lactic bacteria which secrete an acid and give off a gas as well as alcohol. By means of this fermentation the dough, permeated by the gas which raises it, gives a lighter, more digestible bread. We are far from knowing all of the details of the process of bread fermentation. However that may be, for ages beer yeast has been introduced into the leaven, or, as in the time of the Romans, the "must of fermenting wine." These yeasts

'Bateson, "Mendelism," Cambridge, 1909. See "Mendelism," Punnet, R. C., ed. 7, Cambridge, 1909 , p. 58. 
are minute fungi invisible to the naked eye which attack the sugar of the bread and transform it into carbonic-acid gas and alcohol. The course of this fermentation is controlled by the presence of lactic bacteria which prevent the growth of putrefactive organisms. But here again there are lactic bacteria and lactic bacteria, yeasts and yeasts. These yeasts are again populations, mixtures of different races from which the microbiologist can select pure lines. Here Vilmorin's method must be used, $i$. e., filiation from a single isolated germ. Thanks to this process, Hansen and others have selected a large number of strains of yeasts, each with its particular character. For science of to-day beer yeast no longer exists, but in its place there are many distinct and constant species just as there are many distinct and constant species of lactic bacteria. The problem of the future will be, then, to regulate bread fermentation by means of these selected microorganisms.

But certain flours do not rise well. Suitable ferments must be found for them. Others, like maize flour, do not rise at all. It is therefore impossible to make bread from maize alone. In 1900, at the time of the World's Exposition at Paris, I was asked this question: "How can we find a ferment to raise dough made from maize?" No yeast tried up to that time had been able to accomplish this. I then thought of using ferment from India which I had procured through Colonel Prain, director of the Kew Botanic Garden. In applying these selection methods the late Mr. A. Netchich and I obtained from these ferments, which are employed in Sikkim and the Khasia Mountains for the alcoholic fermentation of rice and Eleusine, a leaven, which alone or associated with other yeast causes maize dough to rise and thus allows bread to be made from it. We dedicated this species to Dr. Prain (Amylomyces Prainii=Mucor Prainii). I take this opportunity of announcing this discovery and putting it in reach of all those who wish to profit by it. 




CAGE

7 DAY USE

RETURN TO DESK FROM WHICH BORROWED

Affine. Reference Sorted
This publication is due on the LAST DATE stamped below.

\begin{tabular}{|c|c|}
\hline NoV $1+1962$ \\
\hline \\
\hline
\end{tabular}




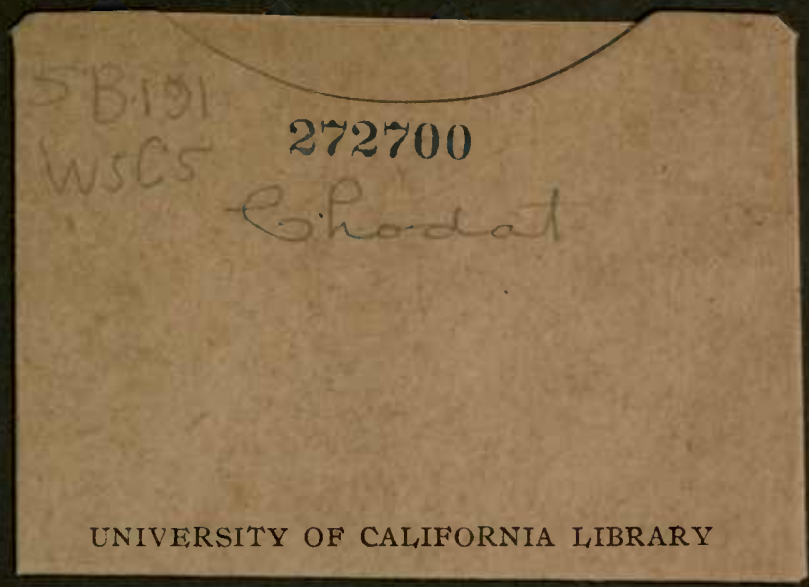


